\title{
New drugs and combinations for the treatment of soft-tissue sarcoma: a review
}

This article was published in the following Dove Press journal:

Cancer Management and Research

22 November 2012

Number of times this article has been viewed

\author{
Neeta Somaiah' \\ Margaret von Mehren² \\ 'Department of Sarcoma Medical \\ Oncology, The University of Texas \\ MD Anderson Cancer Center, \\ Houston, TX, USA; ${ }^{2}$ Department \\ of Medical Oncology, Fox Chase \\ Cancer Center, Philadelphia, PA, USA
}

Correspondence: Margaret von Mehren Department of Medical Oncology, Fox Chase Cancer Center, 333 Cottman Avenue, Philadelphia, PA I9I।I-2497, USA

Tel + I $21572828 \mid 4$

$\mathrm{Fax}+$ I 2157283639

Email margaret.vonmehren@fccc.edu

\begin{abstract}
Sarcomas are a heterogeneous group of solid tumors arising from either soft tissues or bone, accounting for approximately $1 \%$ of all cancers in adults. Management of these diseases has changed little over the past 10 years, with the exception of treatment of gastrointestinal stromal tumors. Reasons for this stagnation include multiple histologies commonly grouped together in clinical trials limiting the understanding of benefit of treatment and limited investigation of molecular targeted therapies. More recently, advances in molecular pathogenesis, the advent of novel and targeted therapeutics, and increasing collaborations between sarcoma investigators has helped move the field forward in the right direction. Here, we review the recent data on novel agents tested for the management of adult soft-tissue sarcomas, excluding gastrointestinal stromal tumors.
\end{abstract}

Keywords: soft tissue sarcoma, clinical trials, trabectedin, palifosfamide, pazopanib

\section{Introduction}

Sarcomas are a histologically and genetically heterogeneous group of solid tumors arising from either soft tissues or bone and are grouped together for their presumed common mesenchymal origin. Soft-tissue sarcomas (STS) constitute a little less than $1 \%$ of all cancers in adults, with around 11,000 new cases per year in the US. ${ }^{1}$ Apart from the groundbreaking discovery of KIT expression and activating mutations in gastrointestinal stromal tumors (GISTs) that transformed this chemo-insensitive, routinely fatal disease to one of the most treatable sarcomas, there has been little progress in sarcoma therapy in the past 10 years. One of the major reasons for this stagnation was because all high-grade STS were being treated similarly on clinical trials. Now, due to a greater understanding of the diversity in molecular pathogenesis and the advent of novel and targeted therapeutics, the field of sarcoma has seen some exciting recent advances. Also, increasing collaboration among sarcoma oncologists nationally and internationally has made large randomized clinical trials in subtypespecific sarcomas feasible. This review focuses on promising new drugs and combination therapies that are changing the therapeutic and investigational landscape of STS, excluding GISTs.

\section{Localized STS}

Surgical resection with or without radiation therapy remains the mainstay of therapy for localized STS. ${ }^{2,3}$ The role of adjuvant therapy remains controversial, fraught with the challenges of performing an adequately powered randomized controlled study in a rare tumor that has tremendous heterogeneity in chemoresponsiveness of the various 
sarcoma subtypes. The majority of the data are with doxorubicin-containing regimens, some of which utilize doxorubicin as a single agent. To address the problem of inadequately powered adjuvant sarcoma studies showing nonsignificant benefit in survival outcomes, the Sarcoma Meta-analysis Collaboration (SMAC) performed a meta-analysis of 14 studies comprising 1568 patients, initially published in 1997. ${ }^{4} \mathrm{Six}$ of these studies evaluated doxorubicin as a single agent, and the other eight used varying combinations of doxorubicin. The 10-year disease-free survival was improved (45\%-55\%, $P=0.0001)$, but 10 -year overall survival did not reach significance $(50 \%-54 \%, P=0.12)$.

An update of the SMAC analysis was published in 2008 and included patients from the 1997 meta-analysis and four additional randomized trials. ${ }^{5}$ The pooled data from a total of 1953 patients demonstrated a statistically significant odds ratio (OR) in favor of adjuvant chemotherapy for local recurrence (OR 0.73, $P=0.02$ ), distant recurrence (OR 0.67, $P=0.001$ ), and overall recurrence (OR 0.67, $P=0.0001$ ). Survival analysis showed a statistically significant benefit for doxorubicin combined with ifosfamide (OR 0.56, 95\% confidence interval [CI] $0.36-0.85 ; P=0.01)$, but not for doxorubicin alone (OR 0.84, 95\% CI 0.68-1.03; $P=0.09$ ). This study did not include the recent European Organization for Research and Treatment of Cancer Soft Tissue and Bone Sarcoma Group (EORTC) study ${ }^{6}$ evaluating adjuvant doxorubicin and ifosfamide versus observation in resected grade 2 and 3 extremity tumors. A separate update of the SMAC meta-analysis including this EORTC study with a total of 2170 patients, presented by O'Connor et al, showed a benefit of adjuvant chemotherapy for disease-free and overall survival after 5 years, but only a nonsignificant trend toward improved survival after 10 years (OR 0.87 , $P=0.12) .{ }^{7}$ A pooled analysis of individual patient data from the two largest adjuvant trials conducted by EORTC ${ }^{6,8}$ using doxorubicin- and ifosfamide-based chemotherapy was also presented the same year and did not show a survival advantage for postoperative chemotherapy. ${ }^{9}$

Based on some retrospective analyses, ${ }^{10,11}$ it has been proposed that the benefit of adjuvant chemotherapy is likely limited to patients with higher-grade and larger tumors with certain chemosensitive histologies (ie, myxoid/round-cell liposarcomas and synovial sarcomas); however, this lacks validation by a prospective clinical trial.

\section{Metastatic STS}

Chemotherapy is widely used in the treatment of nonresectable advanced disease, primarily with palliative intent.
At present, initial standard chemotherapy for advanced or metastatic STS consists of single-agent anthracycline (mainly doxorubicin) or an anthracycline-based combination. Other agents with single-agent activity that are frequently combined with doxorubicin are ifosfamide and dacarbazine. The objective response rate in treatment-naive patients is somewhere between $18 \%$ and $35 \% .{ }^{12}$ The use of doxorubicin is limited, due to its risk of cumulative cardiac toxicity.

Gemcitabine and docetaxel is another frequently used combination as a second-line regimen in STS and occasionally used front-line for uterine leiomyosarcomas, the histology with the highest reported response rates to this combination. ${ }^{13-15}$ A randomized phase II study conducted by Maki et al in metastatic STS suggested a survival benefit for fixed dose-rate gemcitabine with docetaxel over fixed dose-rate gemcitabine alone. ${ }^{16}$ The median progressionfree survival (PFS) of gemcitabine therapy alone was 3 months compared to 6 months with the combination, and the objective response rate was $8 \%$ versus $16 \%$, favoring the combination arm. The median overall survival (OS) was 18 months versus 12 months favoring the gemcitabine and docetaxel combination. Retrospective data from the French Sarcoma Group has demonstrated an overall objective response rate of $18.4 \%$; when stratified by histology, leiomyosarcomas had the best objective response rate at $24.2 \%$, compared with other sarcomas with a response rate of only $10.4 \% .^{17}$

It is now well known that various histologic subtypes respond differently to cytotoxic therapy. As described above, leiomyosarcomas seem to have higher response with gemcitabine and docetaxel. Myxoid liposarcomas and synovial sarcomas have shown significant sensitivity to ifosfamide. ${ }^{18}$ Paclitaxel appears to work well in angiosarcomas. ${ }^{19}$ Some subtypes like GISTs, alveolar soft-part sarcoma (ASPS), clear-cell sarcomas, and well-differentiated liposarcomas are intrinsically resistant to chemotherapy. ${ }^{20}$

As with most tumors, many chemotherapy-sensitive patients will ultimately relapse, and the prognosis for patients with metastatic sarcoma remains poor. The estimated median survival is $8-13$ months from the start of first-line anthracycline-based chemotherapy, as shown in randomized studies performed over the last two decades. ${ }^{21-24}$ In addition, these patients are often debilitated by their sarcoma, as bulky disease can result in complications such as pain, intestinal obstruction, and other symptoms, leading to end-organ failure and death. The median survival for patients for whom conventional chemotherapy with anthracycline and ifosfamide has failed is in the range of 6 months. ${ }^{25-29}$ 
Of note, the current chemotherapy combinations in sarcoma have significant cumulative and late toxicities. The majority of patients require some form of dose adjustment due to toxicity. Newer-generation drugs with a favorable efficacy and toxicity profile are eagerly awaited and will be crucial in improving outcomes for sarcoma patients. It is also essential that we acknowledge the differences between various subtypes in designing sarcoma clinical trials. Patient numbers are the obvious challenge in a rare cancer, but collaborations across institutes and countries are making it feasible to execute such trials and focus on pathogenesisdriven therapies in some rare subtypes.

One of the frequently referenced articles in sarcoma, by Van Glabbeke et al, estimated the progression-free rate (PFR) for active and inactive agents for STS in the firstand second-line setting based on the EORTC clinical trials database. ${ }^{30}$ For first-line therapy, a 6 -month PFR of $30 \%$ or higher suggested drug activity, and for second-line therapy, a 3-month PFR of $40 \%$ or higher was associated with an active drug and $20 \%$ or lower meant inactivity. With more common sarcoma types, histology-specific benchmarks are also available. These provide a reference value for performing phase II studies in sarcoma with PFR as the primary end point.

\section{Novel chemotherapeutics Trabectedin}

Trabectedin (Yondelis [ecteinascidin 743 or ET-743]; Janssen) is a tris(tetrahydroisoquinoline) alkaloid that was initially isolated from the sea squirt Ecteinascidia turbinata. Potent antitumor activity was noted in preclinical studies in vitro and in vivo, in many solid tumors, and was confirmed in several phase II trials in ovarian and breast cancer and STS. The mechanism of action of trabectedin's cytotoxicity is not yet precisely known. It binds to the minor groove on the DNA in a sequence-specific manner and alkylates guanine at the $N^{2}$ position, inducing DNA bending towards the major groove and a widening of the DNA minor groove. ${ }^{31,32}$ This leads to inhibition of activated transcription, and trabectedin interacts with the transcription-coupled nucleotide-excision repair, leading to irreversible breaks in DNA strands, cellcycle arrest, and apoptosis. ${ }^{31-35}$

Four phase I trials testing different doses and schedules of trabectedin established $1.5 \mathrm{mg} / \mathrm{m}^{2}$ given as a continuous infusion over 24 hours as the recommended phase II dose. Responses were seen mainly in STS patients, and this prompted multiple sarcoma-specific trials; some of the published results are tabulated below (Table 1).
Delaloge et al published the clinical activity of trabectedin in sarcoma patients pretreated with doxorubicin and an alkylating agent in 2001, including twelve patients treated on a phase I clinical trial and 17 patients entered on a compassionate-use program. ${ }^{36}$ There were four partial responses (PRs) (14\%), ten disease stabilizations (34\%) lasting more than 2 months, and eight patients (28\%) were progression-free at 6 months. A phase II study in France enrolled 54 patients in two groups: 26 with one or two prior therapies and 28 with three or more prior therapies. ${ }^{37}$ Two patients (3.7\%) had a PR, and nine patients (17\%) had stable disease (SD) for more than 6 months, with 39\% and 24\% patients progression-free at 3 and 6 months, respectively. The median PFS was 1.9 months, similar in both groups, and median OS was 12.8 months (14 months in the first group versus 8 months in the second group). A similar phase II study in the US by Garcia-Carbonero et al reported results in 36 previously treated patients with progressing STS, the majority with either leiomyosarcoma or liposarcoma, using trabectedin $1.5 \mathrm{mg} / \mathrm{m}^{2}$ administered as a 24-hour continuous infusion. ${ }^{38}$ One complete response (CR) and two PRs (objective response rate [ORR], $\mathrm{CR}+\mathrm{PR}=8 \%$ ) were observed, with a median PFS of 1.7 months and median OS of 12.1 months. Another trial of trabectedin $1.5 \mathrm{mg} / \mathrm{m}^{2}$ as a 24-hour continuous infusion was conducted by the EORTC with non-GIST STS failing prior chemotherapy. ${ }^{39}$ The most common histological subtypes were leiomyosarcoma (41\%), synovial sarcoma (17\%), and liposarcoma (10\%). There were eight (7.7\%) PRs and 45 (43.3\%) with SD observed. After a median follow-up of 34 months, the median PFS was 3.4 months (105 days), and the median OS was 9.2 months. Fifty-two percent, $29 \%$, and $17 \%$ of patients were progression-free at 3, 6, and 12 months, respectively. Huygh et al reported their experience with 89 patients who received trabectedin at the Leuven Cancer Institute in Leuven, Belgium: 75 were treated on a compassionate-use program and 15 treated in a phase II trial. ${ }^{40}$ In this group, where the majority (93\%) of patients had previously received doxorubicin, one $\mathrm{CR}$, five PRs (ORR $=7 \%)$, and 32 with SD (36\%) were observed. Median PFS and OS were 2.0 and 8.2 months, respectively. A phase II trial looking at the efficacy of trabectedin in chemotherapy-naive patients accrued 36 patients with either leiomyosarcoma (42\%) or liposarcoma $(25 \%){ }^{41}$ The median PFS was 1.6 months, and the median OS was 15.8 months. Six patients had PR (17\%) and the PFRs were $24.4 \%$ and $21 \%$ at 6 and 12 months, respectively, indicating prolonged disease control in some patients. A multicenter phase II trial in patients with locally advanced or locally recurrent 
Table I List of published sarcoma clinical trials on ET-743

\begin{tabular}{|c|c|c|c|c|c|}
\hline Study & Regimen & $\mathbf{n}$ & RR (RECIST) & PFS (months) & OS (months) \\
\hline \multicolumn{6}{|l|}{ Pretreated } \\
\hline $\begin{array}{l}\text { Delaloge et al }{ }^{36} \text { (phase I+ } \\
\text { compassionate use) }\end{array}$ & $\begin{array}{l}\text { ET-743 } 24 \mathrm{hr} \text { CIV } \\
1.2 \mathrm{mg} / \mathrm{m}^{2}(\mathrm{n}=6) \\
1.5 \mathrm{mg} / \mathrm{m}^{2}(\mathrm{n}=22) \\
1.8 \mathrm{mg} / \mathrm{m}^{2}(\mathrm{n}=1)\end{array}$ & $\begin{array}{l}29 \\
\text { (LMS 28\%, liposarcoma I4\%) }\end{array}$ & $\begin{array}{l}\text { PR I4\% } \\
\text { MR } 7 \% \\
\text { SD } 34 \%\end{array}$ & 2.8 & NR \\
\hline $\begin{array}{l}\text { Yovine et } \mathrm{al}^{37} \\
\text { (phase II) }\end{array}$ & $\begin{array}{l}\text { ET-743 } 24 \mathrm{hr} \text { CIV } \\
\mathrm{I} .5 \mathrm{mg} / \mathrm{m}^{2}\end{array}$ & $\begin{array}{l}54 \\
\text { (LMS 4I\%, liposarcoma II\%) }\end{array}$ & $\begin{array}{l}\text { PR } 4 \% \\
\text { MR } 7 \% \\
\text { SD } 17 \%\end{array}$ & 1.9 & 12.8 \\
\hline $\begin{array}{l}\text { Garcia-Carbonero et al }{ }^{38} \\
\text { (phase II) }\end{array}$ & $\begin{array}{l}\text { ET-743 } 24 \mathrm{hr} \mathrm{CIV} \\
\mathrm{I} .5 \mathrm{mg} / \mathrm{m}^{2}\end{array}$ & $\begin{array}{l}36 \\
\text { (LMS 36\%, liposarcoma 28\%) }\end{array}$ & $\begin{array}{l}\text { CR 3\% } \\
\text { PR 5\% } \\
\text { MR 5\% }\end{array}$ & 1.7 & 12.1 \\
\hline $\begin{array}{l}\text { Le Cesne et al }{ }^{39} \\
\text { (phase II) }\end{array}$ & $\begin{array}{l}\text { ET-743 } 24 \mathrm{hr} \text { CIV } \\
1.5 \mathrm{mg} / \mathrm{m}^{2}\end{array}$ & $\begin{array}{l}\text { I04 } \\
\text { (LMS 4I\%, liposarcoma I0\%) }\end{array}$ & $\begin{array}{l}\text { PR } 8 \% \\
\text { SD } 43 \%\end{array}$ & 3.4 & 9.2 \\
\hline $\begin{array}{l}\text { Huygh et } \mathrm{al}^{140} \\
\text { (phase II + compassionate } \\
\text { use) }\end{array}$ & $\begin{array}{l}\text { ET-743 } 24 \mathrm{hr} \text { CIV } \\
0.9-1.5 \mathrm{mg} / \mathrm{m}^{2}\end{array}$ & $\begin{array}{l}89 \\
\text { (LMS 33\%, liposarcoma I8\%) }\end{array}$ & $\begin{array}{l}\text { CR I\% } \\
\text { PR 6\% } \\
\text { MR I\% } \\
\text { SD I8\% }\end{array}$ & 2.0 & 8.25 \\
\hline $\begin{array}{l}\text { Demetri et al }{ }^{43} \\
\text { (randomized phase II } \\
\text { in L-type sarcomas) }\end{array}$ & $\begin{array}{l}\text { A: } 0.58 \mathrm{mg} / \mathrm{m}^{2} \text { IV } \\
\text { over } 3 \mathrm{hrs} \text { weekly } \\
\text { B: } 1.5 \mathrm{mg} / \mathrm{m}^{2} \text { CIV } \\
\text { over } 24 \mathrm{hrs} \text { every } 3 \text { wks }\end{array}$ & $\begin{array}{l}270 \\
\text { A: } 136 \\
\text { B: I34 } \\
\text { (65.6\% LMS and } 34.4 \% \\
\text { liposarcomas) }\end{array}$ & $\begin{array}{l}\text { A: } \\
\text { I.6\% PR } \\
\text { B: } \\
5.6 \% \text { PR }\end{array}$ & $\begin{array}{l}\text { A: } 2.3 \\
\text { B: } 3.3 \\
P=0.0418\end{array}$ & $\begin{array}{l}\text { A: } 11.8 \\
\text { B: } 13.9 \\
P=0.19\end{array}$ \\
\hline Front line & & & & & \\
\hline $\begin{array}{l}\text { Garcia-Carbonero et } \mathrm{al}^{4 \mathrm{I}} \\
\text { (phase II) }\end{array}$ & $\begin{array}{l}\text { ET-743 } 24 \mathrm{hr} \mathrm{CIV} \\
\mathrm{I} .5 \mathrm{mg} / \mathrm{m}^{2}\end{array}$ & $\begin{array}{l}36 \\
\text { (LMS 42\%, liposarcoma 25\%) }\end{array}$ & $\begin{array}{l}\text { CR 3\% } \\
\text { PR I4\% } \\
\text { MR 3\% }\end{array}$ & 1.6 & 15.8 \\
\hline
\end{tabular}

Abbreviations: LMS, leiomyosarcoma; RECIST, Response Evaluation Criteria in Solid Tumors; RR, response rate; PFS, progression-free survival; OS, overall survival; CIV, continuous infusion; PR, partial response; MR, minor response; SD, stable disease; CR, complete response; IV, intravenous.

myxoid/round-cell liposarcoma, with three to six cycles of trabectedin in the neoadjuvant setting resulted in encouraging pathologic $\mathrm{CR}$ rates of $13 \%(95 \% \mathrm{CI}, 3 \%-34 \%) .{ }^{42}$

Results of a randomized phase II trial comparing trabectedin given at $580 \mu \mathrm{g} / \mathrm{m}^{2}$ over 3 hours on a weekly schedule to a schedule of $1.5 \mathrm{mg} / \mathrm{m}^{2}$ 24-hour continuous infusion every 3 weeks in patients with leiomyosarcoma or liposarcoma failing prior therapy with doxorubicin and ifosfamide favored the 24-hour infusion every 3 weeks. ${ }^{43}$ Two hundred and seventy patients were randomly assigned, and the primary end point of time to progression was 3.7 months versus 2.3 months (hazard ratio [HR] $0.734 ; 95 \%$ CI $0.554-0.974 ; P=0.0302$ ), and the median OS was 13.9 months versus 11.8 months (HR $0.843,95 \%$ CI $0.653-1.090 ; P=0.1920$ ) in the 3-hour weekly versus 24-hour every-3-week schedule, respectively.

Trabectedin is generally well tolerated, and some responding myxoid liposarcoma patients stay on therapy for more than 12 months. The most common grade 3 or 4 toxicities seen in the phase II trials are neutropenia, thrombocytopenia, and biochemical hepatotoxicity. Nausea, vomiting, and fatigue are also frequently noted. Rare cases of fulminant hepatic failure and rhabdomyolysis have also been reported. An abnormal baseline alkaline phosphatase and a bilirubin $>0.6 \times$ upper limit of normal is predictive of severe hematologic and hepatic toxicity in patients receiving trabectedin. ${ }^{44,45}$ Steroid premedication has been reported to reduce biochemical and hematologic toxicity, ${ }^{46}$ and this in addition to more stringent hepatic function parameters and dose-reduction guidelines has decreased the incidence of severe toxicities in recent trials.

Trabectedin was approved by the European Union in 2007 for the treatment of patients with STS who progress on or are not candidates for anthracycline- or ifosfamide-based therapy. In the US, a randomized phase III registration trial of trabectedin versus dacarbazine for previously treated patients with leiomyosarcoma and liposarcoma (L-type sarcomas) is currently accruing patients. The expanded access program for nonL-type sarcomas is also open in the US to facilitate access to trabectedin in patients unlikely to benefit from other standardof-care treatments. Some of the other ongoing trials include a phase IIB/III study comparing the efficacy of trabectedin administered as a 3-hour or 24-hour infusion to doxorubicin in patients with advanced untreated STS and a similar phase III trial specific to patients with translocation-related sarcomas 
looking at trabectedin over 24 hours versus doxorubicin-based chemotherapy as front-line therapy.

\section{Palifosfamide}

Palifosfamide (Zymafos [isophosphoramide mustard, ZIO 201]; Ziopharm) is a novel DNA alkylator and the active metabolite of ifosfamide, thus lacking the hemorrhagic cystitis and central nervous system toxicity associated with the nonactive ifosfamide metabolites. Isophosphoramide mustard has demonstrated broad activity against human sarcoma cell lines in vitro and in vivo, including in cyclophosphamideresistant osteosarcoma xenograft models. ${ }^{47}$ Enhanced antitumor activity was seen with the addition of doxorubicin to palifosfamide in tumor xenografts. ${ }^{48}$

The initial phase I study in solid tumors and a phase I/II study in previously treated sarcoma patients used the lysine salt formulation of palifosfamide as a single agent, with the tris formulation (ZIO-201-T) introduced in the second study after an amendment. ${ }^{49}$ The phase II portion of the study reported a PR in a liposarcoma patient and PFS at 3 and 6 months as $45 \%$ and $23 \%$, respectively. ${ }^{50}$ The combination of doxorubicin with palifosfamide-tris was evaluated in a phase I study, and the maximum tolerated dose (MTD) was determined to be $150 \mathrm{mg} / \mathrm{m}^{2}$ IV (intravenously) daily $\times 3$ days for palifosfamide-tris and $75 \mathrm{mg} / \mathrm{m}^{2} \mathrm{IV}$ on day 1 for doxorubicin repeated every 3 weeks. This led to a phase II randomized trial of palifosfamide-tris plus doxorubicin versus doxorubicin alone in first- and second-line STS (PICASSO). Patients were stratified according to age $(\geq$ or $<65)$ and histologic subtype (leiomyosarcoma, synovial sarcoma, or other) and received a total of six cycles at the phase I MTD dose. Nonprogressing patients after six cycles on the combination arm were eligible to continue single-agent palifosfamide, and patients progressing on single-agent doxorubicin were allowed to receive single-agent palifosfamide. A total of 62 patients were evaluable and the median PFS, which was the primary end point, was 7.8 months for the combination versus 4.4 months for doxorubicin (HR 0.427 [95\% CI $0.19-0.95] ; P=0.019) .{ }^{51}$ The response rate was $23 \%$ for the combination arm and $9 \%$ for doxorubicin alone. A recent press release from Ziopharm reported a positive trend in OS favoring the palifosfamide arm, with an HR of 0.79 in the intention-to-treat population. Common adverse events related to palifosfamide-tris in combination with doxorubicin include nausea, vomiting, fatigue, anemia, neutropenia, leucopenia, constipation, electrolyte abnormalities, and mucosal inflammation. No significant differences in toxicities between the two arms have been reported.
The phase III randomized, double-blind study of doxorubicin plus palifosfamide versus doxorubicin plus placebo has just completed enrollment of the target 424 patients. The study is powered for PFS as the primary end point for accelerated approval and OS for full approval. If positive, this combination is likely going to change the treatment paradigm for sarcomas, given its advantages over the combination of doxorubicin and ifosfamide: safe for outpatient administration and an improved safety profile.

\section{TH-302}

TH-302 (Threshold Pharmaceuticals) is a nitroimidazole prodrug of the cytotoxin bromo-isophosphoramide mustard (Br-IPM). When exposed to hypoxic conditions, TH-302 is reduced at the nitroimidazole site by intracellular reductases, leading to the release of the alkylating agent Br-IPM. ${ }^{52}$ Br-IPM is similar in action to the active metabolite of ifosfamide, IPM, but because of the preferential activation in hypoxic tissues and the absence of acrolein as a by-product, TH-302 is anticipated to have less renal, central nervous system, and bladder toxicity than ifosfamide. In vitro cytotoxicity and clonogenic assays indicate that TH-302 has little activity under normoxic conditions, but is highly cytotoxic under hypoxic conditions. In addition, studies in xenograft models of sarcoma and non-small cell lung cancer (NSCLC) show that TH-302 adds to the activity of maximally tolerated doses of doxorubicin, leading to tumor regressions and growth delay.

Two phase I studies were conducted to determine the safety, efficacy, and pharmacokinetics of TH-302; one was with single-agent TH-302 in advanced solid tumors, ${ }^{53}$ and the other was in combination with full-dose doxorubicin in subjects with STS. ${ }^{54}$ In the combination study, the MTD of TH-302 was determined to be $300 \mathrm{mg} / \mathrm{m}^{2}$ IV on days 1 and 8 in combination with $75 \mathrm{mg} / \mathrm{m}^{2} \mathrm{IV}$ of doxorubicin on day 1 , with prophylactic growth-factor support added due to grade 4 neutropenia. Five out of 15 evaluable patients had a PR. Enrollment was expanded at the MTD for subjects with advanced STS previously untreated with chemotherapy (neoadjuvant and adjuvant chemotherapy permitted), and updated results from this phase II portion of the study were reported at the 2011 Connective Tissue Oncology Society (CTOS) meeting. ${ }^{55}$ Patients received up to six cycles of the combination, and nonprogressing patients with acceptable toxicity were allowed to continue single-agent TH-302. Tumor response rates for the 89 evaluable patients out of the 91 enrolled were as follows: CR (2) $2 \%$, PR (30) $34 \%$, SD (43) $48 \%$, and PD (14) 16\%. The median PFS was 6.7 months 
(95\% CI, 6.2-8.1 months). The 6-month PFR was 63\%, and the 3-month PFR was $83 \%$. The median OS was 17.5 months (95\% CI, 16.1 months to not reached). The tumor response, PFS, and OS are all higher than those reported historically with single-agent doxorubicin. The combination regimen was well tolerated with acceptable grade 3 and 4 hematologic toxicities and some grade 3 fatigue, diarrhea, and pyrexia. Skin and mucosal toxicities related to activation of the TH-302 in these tissues were noted, and supportive measures such as application of ice to these areas during infusion is recommended.

The phase III randomized study of doxorubicin versus doxorubicin and TH-302 as front-line therapy in patients with advanced STS has recently started accruing patients and will help us ultimately determine the value of this combination in the sarcoma armamentarium.

\section{Eribulin}

Eribulin mesylate (Halaven; Eisai) is a synthetic analogue of halichondrin B, a novel inhibitor of microtubule dynamics, extracted from the marine sponge Halichondria okadia. Eribulin is FDA-approved for the treatment of metastatic breast cancer in patients who have received at least two prior lines of therapy for late-stage disease. Based on preclinical activity seen in fibrosarcoma and leiomyosarcoma xenograft models, EORTC conducted a phase II nonrandomized multicenter trial for patients with high-grade sarcoma, who had received no more than two prior chemotherapeutic agents for advanced disease. ${ }^{56}$ In this EORTC trial 62052, eribulin was given intravenously at a concentration of $1.4 \mathrm{mg} / \mathrm{m}^{2}$ over 2-5 minutes on days 1 and 8 every 3 weeks with the primary end point of PFS at 12 weeks. Patients were prestratified based on tumor subtype into four categories; leiomyosarcoma, adipocytic sarcoma, synovial sarcoma, and other defined soft-tissue sarcomas. Twelve of the $38(32 \%)$ leiomyosarcoma patients and 15 of the $32(47 \%)$ adipocytic sarcoma patients were progression-free at 12 weeks, whereas only four of the 19 (21\%), and five of the 26 (19\%) patients with synovial sarcoma and other sarcomas, respectively, were progressionfree at 12 weeks. The most common grade 3-4 adverse events were neutropenia (52\%), leucopenia (35\%), anemia $(7 \%)$, fatigue $(7 \%)$, febrile neutropenia $(6 \%)$, abnormal alanine aminotransferase concentrations (5\%), mucositis $(3 \%)$, and sensory neuropathy $(3 \%)$.

A phase III trial comparing eribulin to dacarbazine in patients with intermediate to high-grade advanced liposarcoma or leiomyosarcoma who have progressed after standard therapy is ongoing. This is similar to the trabectedin trial, and OS is the primary end point.

\section{Targeted therapies}

A variety of drugs targeting the molecular pathways involved in carcinogenesis are also being investigated in sarcomas, as more data are emerging regarding the molecular aberrations in this heterogeneous group of diseases. Detailed below are some agents that have shown encouraging activity, starting with pazopanib, an antiangiogenic agent that recently became the first molecular-targeted therapy to be FDA-approved in STS. Figure 1 highlights the targets for the agents discussed in this section.

\section{Angiogenesis inhibitors Pazopanib}

Pazopanib (Votrient [GW786034]; GlaxoSmithKline) is an orally bioavailable, adenosine triphosphate-competitive tyrosine kinase inhibitor of vascular endothelial growthfactor receptor (VEGFR)-1, -2, and -3, platelet-derived growth-factor receptor (PDGFR)- $\alpha$ and $-\beta$, and v-kit HardyZuckerman 4 feline sarcoma viral oncogene homolog (c-kit) that has activity in multiple cancers, including renal cell cancer, sarcoma, NSCLC, and cervical and ovarian cancer. It is FDA-approved for the treatment of advanced renal-cell carcinoma and was recently approved for the treatment of patients with advanced STS who have received prior chemotherapy, excluding GIST and adipocytic STS patients. Sarcomas appear to be a good tumor type for antiangiogenic inhibitors, particularly those preventing VEGF action. ${ }^{57}$ Circulating angiogenic factor levels were shown to correlate with extent of disease and risk of recurrence in patients with STS. ${ }^{58}$ Pazopanib was evaluated as a single agent in STS in an EORTC phase II trial, and showed single-agent activity in STS, including leiomyosarcoma and synovial sarcomas, but not in adipocytic tumors. ${ }^{59}$ This was followed by a randomized phase III placebo-controlled study of pazopanib in previously treated STS patients that showed a statistically significant improvement in PFS, leading to the recent approval. The $800 \mathrm{mg}$ daily dosing regimen is the established active monotherapy dose used in these trials, providing optimal biologic and clinical effects associated with VEGFR inhibition and generally well tolerated.

The phase II study of pazopanib in patients with relapsed or refractory STS used a Simon two-stage design to evaluate the primary end point of PFR, using RECIST at 12 weeks after start of treatment, in four different STS categories. ${ }^{59}$ Patients with leiomyosarcoma, synovial sarcoma, and 


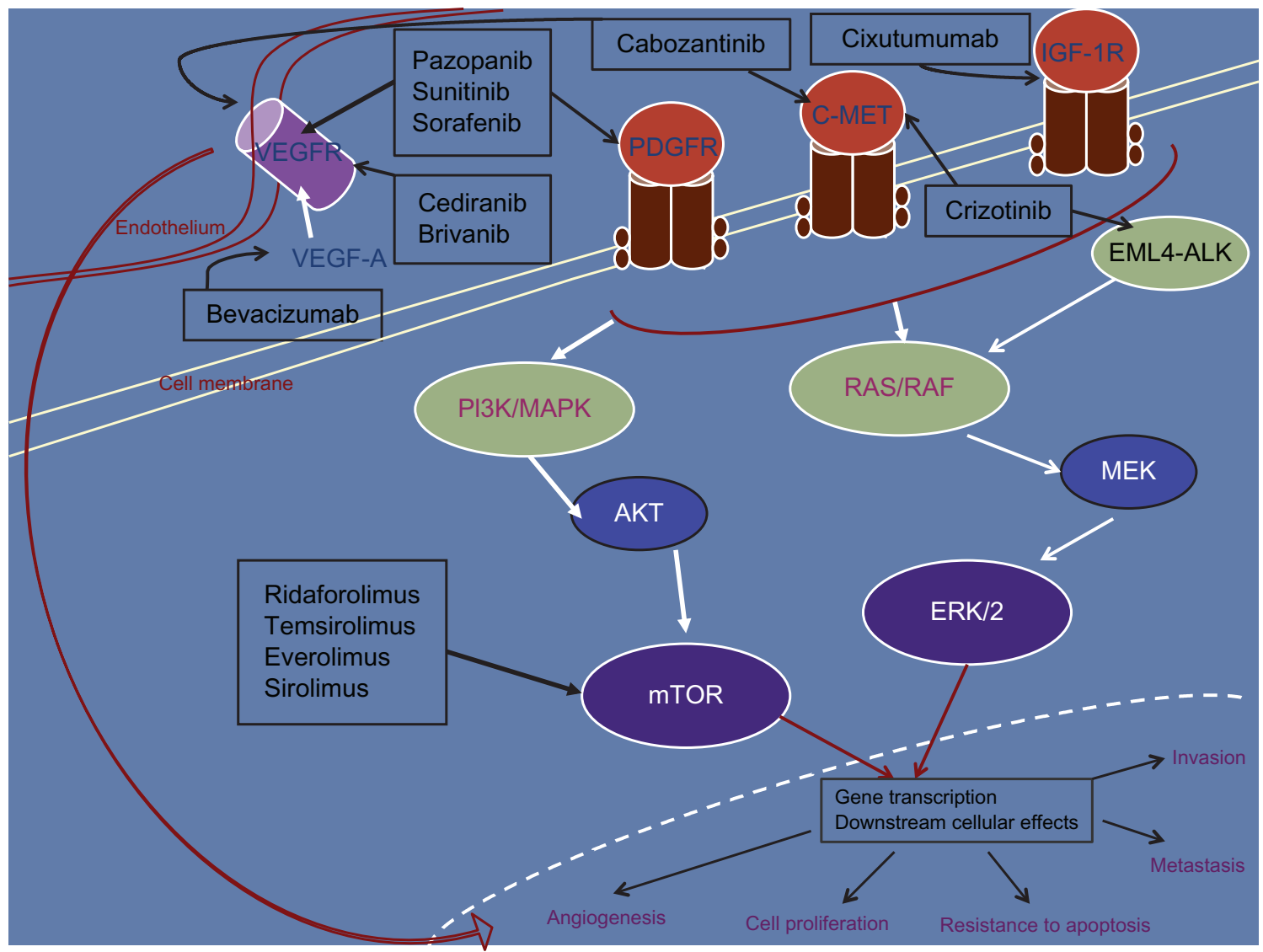

Figure I Molecular-targeted therapy with activity in soft-tissue sarcoma. Only the major target(s) for each of the inhibitors have been depicted.

Abbreviations: VEGFR, vascular endothelial growth-factor receptor; STS, soft-tissue sarcoma; PDGFR, platelet-derived growth-factor receptor; IGF-IR, insulin-like growth factor-I receptor; PI3K, phosphatidylinositol 3-kinase; MAPK, mitogen-activated protein kinase; EML4, echinoderm microtubule-associated protein-like 4; ALK, anaplastic lymphoma kinase; MEK, mitogen-activated protein kinase; ERK, extracellular signal-regulated kinases; AKT, protein kinase B; mTOR, mammalian target of rapamycin.

"the other types of sarcoma" experienced a 12-week PFR of $\geq 40 \%$, the predefined threshold indicating antitumor activity. The liposarcoma group did not meet its prespecified end point at the end of stage 1 and did not progress to stage 2 . A total of 142 patients were enrolled and there were nine documented PRs, with at least 14 patients receiving more than 1 year of protocol therapy. The phase III randomized, doubleblind study of pazopanib versus placebo in subjects with STS, excluding patients with GIST or adipocytic sarcomas (PALLETE), was initiated in 2008. A total of 369 STS patients, who had received at least one prior anthracycline-containing regimen were randomized in a 2:1 ratio to pazopanib or placebo. ${ }^{60}$ Results published this year showed patients on the pazopanib arm had a statistically significant improvement in PFS, with a median increase of 13 weeks (median PFS 4.6 months versus 1.6 months; $\mathrm{HR}=0.31$ (95\% CI $0.24-0.40), P<0.0001)$. OS showed a trend toward improvement, but was not statistically significant (median 12.5 versus 10.7 months; HR $=0.86$ [95\% CI $0.67-1.11])$. The median relative-dose intensity of pazopanib was $768 \mathrm{mg}$ daily.
The most common adverse events reported for pazopanib monotherapy to date are diarrhea, fatigue, nausea, hypertension, hair color changes (hair depigmentation), anorexia, vomiting, dysgeusia, headache, abdominal pain, rash, aspartate aminotransferase (AST), and alanine aminotransferase (ALT) increases, constipation, cough, and arthralgia. The majority of these events are low-grade. The most frequent grade 3 or 4 toxicities include hypertension, fatigue, diarrhea, hyperbilirubinemia, and AST and ALT increases. Less common adverse events of note include hand-foot syndrome, mucositis/stomatitis, proteinuria, venous thrombotic events, and bleeding.

Future studies in sarcoma are focusing on pazopanib's role in earlier lines of therapy, in specific histologic subtypes, and in combination with chemotherapeutic agents.

\section{Sorafenib}

Sorafenib (BAY 43-9006; Onyx Pharmaceuticals) is an oral multikinase inhibitor with antiangiogenic and proapoptotic properties, targeting wild-type and mutant B-raf and 
C-raf kinases, as well as VEGFR-2, PDGFR- $\beta$, fms-like tyrosine kinase 3 (Flt-3), c-KIT and p38a, a member of the MAP kinase family. PDGFR expression has been demonstrated in sarcomas, and hence is a target of interest in addition to VEGFR. ${ }^{61,62}$ Sorafenib is currently FDA-approved for unresectable hepatocellular carcinoma and renal-cell carcinoma.

Based on an encouraging 12-week nonprogression rate seen in metastatic sarcoma patients in a phase I study, ${ }^{63}$ Maki and his colleagues conducted a phase II multiarm study with single-agent sorafenib at a dose of $400 \mathrm{mg}$ twice daily in patients with advanced STS. ${ }^{64}$ Each of the six arms, representing different subtypes, including leiomyosarcoma, malignant peripheral nerve-sheath tumor, synovial sarcoma, vascular sarcomas, high-grade undifferentiated pleomorphic sarcoma, and "other" sarcomas, had its own Simon twostage design. Out of the 145 patients treated on the study, 144 were evaluable for toxicity, and 122 were evaluable for response. Sixty-three percent of patients had received prior chemotherapy. Clinical response was only seen in the leiomyosarcoma and angiosarcoma subtypes, and the angiosarcoma arm was the only arm to meet the RECIST response-rate primary end point with five out of 37 patients responding (one CR and four PRs). The PFS (Kaplan-Meier estimates) at 3 and 6 months was $53 \%$ and $22 \%$, respectively, and the median OS was 14.3 months (95\% CI, 12.2-19.2 months).

A similar phase II trial conducted through the Southwest Oncology Group (SWOG) evaluated the role of sorafenib in advanced vascular sarcomas (angiosarcomas, malignant hemangiosarcomas, and solitary fibrous tumors), grade 3 and 4 liposarcomas and leiomyosarcomas, based on known expression of VEGFR and PDGFR in these histologies. ${ }^{65}$ Of the 37 patients evaluable for response and toxicity, no confirmed responses were documented. The median PFS was 3 months (95\% CI, 2-5 months), and OS was 17 months (95\% CI, 13-25 months). The vascular sarcoma group had the longest median PFS of 5 months (95\% CI, 3-6 months). A third phase II trial in advanced angiosarcomas by the French Sarcoma Group showed minimal activity, with a 40\% tumor control rate and a $23 \%$ response rate only in patients who had previously received conventional chemotherapy. ${ }^{66}$

One of the most common toxicities reported with sorafenib is dermatologic, with the most severe symptoms observed within the first 2 weeks of treatment. A majority of patients required a dose interruption and or reduction in these studies. Other antiangiogenic class effects, including hemorrhage, deep venous thrombosis, bowel perforation, and congestive heart failure, though rare, have also been reported.
Sorafenib also appears to have activity in desmoid fibromatosis, a tumor that lacks metastatic potential but can be locally aggressive, leading to significant morbidity. A retrospective review of 26 patients treated at a single institution, out of which 23 had documented progression prior to sorafenib, revealed a $25 \% \mathrm{PR}$ rate and $70 \% \mathrm{SD}$ rate. ${ }^{67}$ Imatinib (Gleevec [ST1571]; Novartis) was the first tyrosine kinase inhibitor to demonstrate clinical benefit in this disease with validation in a prospective clinical trial. ${ }^{68}$

In the hopes of improving antitumor activity, sorafenib is being combined with conventional chemotherapeutic agents in ongoing phase I/II clinical trials.

\section{Sunitinib}

Sunitinib (Sutent [SU11248]; Pfizer) is another multitargeted, small-molecule inhibitor of the receptor tyrosine kinases involved in tumor proliferation and angiogenesis, including VEGFR-1, -2 , and -3 , PDGFR- $\alpha$ and $-\beta$, KIT, the tyrosine kinase receptor encoded by the ret proto-oncogene, and Flt3. It is approved for use in GIST, renal cell, and pancreatic neuroendocrine tumors. The standard dosing is considered to be $50 \mathrm{mg}$ daily for 4 weeks followed by 2 weeks off, but continuous dosing with $37.5 \mathrm{mg}$ daily might be equally efficacious and hence has been incorporated in more recent trials. ${ }^{69}$

A phase II trial in non-GIST sarcoma patients reported by George et al looked at continuous dosing with $37.5 \mathrm{mg}$ daily, with RECIST response as the primary end point. ${ }^{70}$ One patient with desmoplastic small-round cell tumor achieved a confirmed PR that was durable, and prolonged SD beyond 16 weeks was seen in two patients with solitary fibrous tumor, one each with ASPS, giant-cell tumor of bone, and synovial sarcoma, as well as four patients with chordoma. A retrospective series comprising 35 patients with solitary fibrous tumors also showed clinical activity for sunitinib in this population. ${ }^{71}$ A phase II trial of sunitinib in previously treated metastatic uterine leiomyosarcoma patients, however, revealed minimal activity in this subtype. ${ }^{72}$

Ongoing studies with sunitinib in sarcoma are focusing on its role in certain subtypes like ASPS and vascular sarcomas.

\section{Brivanib}

Brivanib (BMS-540215; Bristol-Myers Squibb) is an oral, selective dual inhibitor of VEGF and fibroblast growth factor (FGF) signaling. Results from a randomized discontinuation phase II trial, with the primary end point being PFS of brivanib versus placebo in sarcoma patients with FGF2 
overexpression by immunohistochemistry, were recently reported. ${ }^{73}$ Brivanib $800 \mathrm{mg}$ once daily was initially given to 251 previously treated sarcoma patients for 12 weeks, after which the patients with PR $(\mathrm{n}=7$, including three angiosarcomas) were continued on brivanib open-label, and patients with progressive disease were taken off therapy. The patients with SD $(n=76)$ were then randomized 1:1 to either brivanib or placebo and stratified by FGF2 expression (53 positive/23 negative). Patients who received placebo were eligible to receive brivanib as open-label at the time of progression. PFS from week 12 in FGF2-positive patients demonstrated a doubling of PFS from 1.4 to 2.8 months (HR $0.58,90 \%$ CI $0.34-0.97 ; P=0.08$ ). In the smaller FGF2negative subset, brivanib demonstrated an improvement in PFS from 1.4 to 2.6 (HR $0.80,90 \%$ CI $0.36-1.79 ; P=0.69$ ). This trial was not powered to determine a difference in efficacy between FGF2-positive and -negative patients. The most common grade 3 or 4 adverse effects included fatigue and hypertension.

\section{Cediranib}

Cediranib (Recentin [AZD2171]; AstraZeneca) is a potent oral pan-VEGFR signaling inhibitor that has shown activity in patients with ASPS, a rare tumor accounting for $<1 \%$ of STS. ASPS is typically indolent but has a high incidence of metastasis to the lung, and can also spread to the brain. It is a highly vascular tumor and does not respond to conventional chemotherapy. A preliminary report of seven patients with ASPS treated with cediranib at a starting dose of $45 \mathrm{mg}$ once daily on two separate phase II trials showed an encouraging response: four patients experienced a $\mathrm{PR}$, two patients had a confirmed reduction in maximum tumor diameter of $\geq 10 \%$ and $<30 \%$, and one patient experienced SD. ${ }^{74}$

Thereafter, a phase II trial of cediranib in patients with ASPS was initiated to determine the response rate, effect on tumor angiogenesis, and proliferation via imaging and to evaluate changes in the gene-expression profile on pre- and posttreatment tumor biopsies. ${ }^{75}$ Patients received $30 \mathrm{mg}$ cediranib orally once a day in 28-day cycles. At the time of this report, 28 patients were evaluable for response, with a disease control rate $(\mathrm{PR}+\mathrm{SD})$ of $78 \%$ at 6 months; 12 patients had PR (43\%), 4 patients had $>20 \%$ reduction in target lesions, and six were stable at 6 months. Common toxicities reported were transaminitis, hypertension, diarrhea, tumor pain, and proteinuria. Preliminary data from geneexpression profiling of five patients revealed an early effect of treatment, with downregulation of certain proangiogenic or endothelial-specific genes and upregulation of genes involved in the inflammatory response. This and other studies are ongoing to confirm the role of cediranib in ASPS.

\section{Bevacizumab}

Bevacizumab (Avastin; Genentech/Roche) is a monoclonal antibody to circulating VEGF and has been evaluated as a single agent or in combination with various chemotherapy agents in the management of metastatic STS. It is FDAapproved for the treatment of metastatic colorectal cancer, non-small cell lung cancer, renal cell cancer and glioblastoma multiforme.

An open-label, single-agent phase II study of bevacizumab was conducted in relapsed or refractory angiosarcoma and epithelioid hemangioendothelioma patients. ${ }^{76}$ Bevacizumab at $15 \mathrm{mg} / \mathrm{kg}$ IV every 3 weeks resulted in a response rate of $12 \%$ and tumor stabilization rate of $62 \%$ among the 26 patients evaluable for response. Two case reports have also reported dramatic responses in cutaneous angiosarcoma, one with bevacizumab monotherapy and one in combination with paclitaxel. ${ }^{77,78}$

Bevacizumab at $15 \mathrm{mg} / \mathrm{kg}$ IV was combined with doxorubicin $75 \mathrm{mg} / \mathrm{m}^{2}$ IV repeated every 3 weeks in a phase II study for metastatic STS. ${ }^{79}$ However, the response rate of 12\% (two PRs out of 17 patients) did not compare favorably to the historical response rate of single-agent doxorubicin. In addition, $35 \%$ of patients had a grade 2 or worse decline in left ventricular ejection fraction, despite administering dexrazoxane once doxorubicin doses exceeded $300 \mathrm{mg} / \mathrm{m}^{2}$. A phase IB study combining docetaxel, gemcitabine, and bevacizumab in patients with chemotherapy-naive STS was also completed. ${ }^{80}$ Gemcitabine was given at three dose levels $\left(1000,1250\right.$, and $\left.1500 \mathrm{mg} / \mathrm{m}^{2}\right)$ every 2 weeks in the dose-finding portion of the study, followed by the expansion cohort with gemcitabine at $1500 \mathrm{mg} / \mathrm{m}^{2}$, docetaxel at $50 \mathrm{mg} / \mathrm{m}^{2}$, and bevacizumab at $5 \mathrm{mg} / \mathrm{kg}$ every 2 weeks. The overall response rate observed in the 35 assessable patients was $31.4 \%$, with five CRs and six PRs, and $51.4 \%$ with SD lasting for a median of 6 months. There was no significant hematologic toxicity. Unfortunately, the observed grade 3 and 4 toxicities attributed to bevacizumab included pneumothorax, bowel perforation, fatigue, skin ulceration, and hemorrhage. Serum and tissue VEGF-A biomarkers studied did not show correlation with outcome. The best responses were seen in the angiosarcoma patients. A retrospective case series of 14 patients reported a $79 \%$ response rate for the combination of temazolomide $150 \mathrm{mg} / \mathrm{m}^{2}$ orally on days $1-7$ and 15-21 along with bevacizumab $5 \mathrm{mg} / \mathrm{kg}$ on days 8 and 22, in patients with solitary fibrous tumors/hemangiopericytomas. ${ }^{81}$ 
Eleven patients demonstrated a PR and two patients had SD based on Choi criteria. ${ }^{82}$

Bevacizumab is actively being investigated in combination with a variety of standard chemotherapy regimens in STS subtypes. One would need to consider the added toxicity while determining the benefit of increased efficacy with combination therapy.

\section{Insulin growth factor-receptor inhibitors \\ Cixutumumab}

Cixutumumab (IMC-A12; Imclone Systems) is a fully human immunoglobulin G1 monoclonal antibody that selectively inhibits the insulin-like growth factor-1 receptor (IGF-1R), sparing the insulin receptor. Insulin growth factor (IGF)-1 and IGF-2 bind to IGF-1R, activating the receptor, and stimulate intracellular signaling, primarily through the downstream Ras/Raf/mitogen-activated protein kinase (MAPK) and the phosphatidylinositol 3-kinase (PI3-K)/AKT/mammalian target of rapamycin (mTOR) pathways. The IGF pathway plays a major role in cancer-cell proliferation, survival, and resistance to therapy and has been implicated in the pathogenesis of various types of bone and soft-tissue sarcoma. . $^{83,84}$

Phase I studies of IGF-1R monoclonal antibodies reported objective responses in several Ewing's sarcoma patients and disease stabilization in one patient each with fibrosarcoma and ASPS. ${ }^{85,86}$ This prompted a few phase II studies, including a study of cixutumumab in five subtypes of sarcoma, with PFS as the primary end point. ${ }^{87}$ One hundred and thirteen patients with previously treated metastatic soft-tissue sarcoma and the Ewing family of tumors were enrolled. Cixutumumab was given intravenously at $10 \mathrm{mg} / \mathrm{kg}$ over 1 hour every other week until disease progression or discontinuation for other reasons. The only subtype to meet the response criteria to proceed to stage 2 of the enrolment based on a Simon two-stage design was the adipocytic tumor. One patient experienced PR, and $57 \%$ of patients experienced SD in this subgroup. Other evidence of activity included one PR in the Ewing sarcoma subtype and SD in $41 \%$ of leiomyosarcoma, $35 \%$ of synovial sarcoma, 28\% of Ewing's, and 24\% of rhabdomyosarcoma patients. Grade 3 or 4 toxicities with single-agent therapy were rare, and included hyperglycemia, asthenia, pain, and thrombocytopenia.

Since mTOR is involved in signal transduction downstream of IGF-1R, combination therapy with an mTOR inhibitor can potentially enhance IGF-1R inhibition. In turn, IGF-1R inhibition could mitigate the activation of upstream signaling molecules that occurs with mTOR inhibition.
Preclinical data support the additive antitumor effects of combining these two targeted agents. ${ }^{88}$ Cixutumumab at $6 \mathrm{mg} / \mathrm{kg}$ IV weekly was combined with temsirolimus, an mTOR inhibitor at 25-37.5 mg IV weekly in 4-week cycles, in heavily pretreated patients with the Ewing family of tumors. ${ }^{89}$ This was well tolerated, with preliminary evidence of durable antitumor activity. Of the 20 patients (17 Ewing's 3 DSRCT) enrolled, seven (35\%) achieved a CR/PR or SD for more than 5 months. The same combination has also been evaluated in a phase II study for STS and bone tumors, stratifying for the expression of IGF-1R on tumor tissue. ${ }^{90}$ These recently reported data showed each of the three arms: IGF-1R-positive STS (A), IGF-1R-positive bone sarcoma (B), and IGF-1R-negative bone and STS (C) met the primary end point of improved PFS, and the effect was independent of IGF-1R expression by immunohistochemistry. By intentionto-treat analysis, the median PFS in weeks was 6.3 (95\% CI 5.9-12.0) for arm A, 11.0 (95\% CI 8.0-18.0) for arm B, and 11.6 (95\% CI 9.0-17.9) for arm C. Adverse events reported are higher with combination therapy, though grade 3 or 4 toxicities were rare (lymphopenia and mucositis).

Cixutumumab is also being evaluated in a phase I study in combination with doxorubicin in advanced STS patients. ${ }^{91}$ Dose-limiting toxicities reported so far have been hyperglycemia and mucositis, with two patients experiencing grade 3 decrease in cardiac ejection fraction after repeated cycles.

\section{mTOR inhibitors}

\section{Ridaforolimus}

The mTOR is a member of the phosphatidylinositol kinaserelated kinase family and functions to regulate protein translation, cell-cycle progression, and cellular proliferation..$^{92,93}$ Activating mutations in growth-factor receptors lead to activation of the downstream PI3K/AKT/mTOR pathway. Ridaforolimus (AP23573; Ariad Pharmaceuticals/Merck) is derived from rapamycin, an immunosuppressive agent, and functions as an mTOR inhibitor, leading to $\mathrm{G}_{1}$ arrest and inactivation of protein synthesis. Based on early evidence of some activity in sarcoma, a phase II study in advanced bone sarcoma and STS was conducted, with ridaforolimus given at $12.5 \mathrm{mg}$ /day IV for 5 days every 2 weeks. ${ }^{94}$ Of the total 212 patients, $61(28.8 \%)$ achieved clinical benefit, though the response rate was only $1.9 \%$ in this heavily pretreated population. Median PFS was 15.3 weeks, and median OS was 40 weeks. No potential tumor markers for response were identified out of those analyzed. Toxicities commonly associated with ridaforolimus include mild to moderate stomatitis, mucosal inflammation, rash, and fatigue. 
Data from the phase III Sarcoma Multi-Center Clinical Evaluation of the Efficacy of Ridaforolimus (SUCCEED) study were first reported in $2011 .^{94}$ Efficacy of oral ridaforolimus was evaluated in the maintenance setting, with 711 patients with SD or better after first-line chemotherapy, randomized to either maintenance ridaforolimus or placebo. The study met its primary end point, with a statistically significant improvement in PFS of 3.1 weeks (17.7 versus 14.6 weeks) favoring ridaforolimus, but there was no significant improvement in OS. Due to this marginal benefit with added side effects in the maintenance setting, the FDA did not approve ridaforolimus for this indication.

\section{Temsirolimus}

Temsirolimus (Toricel [CCI-779]; Wyeth) is another mTOR inhibitor that has been studied in STS patients. A phase II study in 41 patients with advanced STS showed limited activity and moderate toxicity as a single agent, with two patients experiencing a PR and a median time to progression of 2 months. ${ }^{95}$ Temsirolimus in combination with IGF-1R inhibitor cixutumumab showed activity in refractory Ewing sarcoma patients, and this combination is also being evaluated for soft-tissue and bone sarcomas, as described above under IGF-1R receptor inhibitors.

\section{Everolimus}

Everolimus (Afinitor [RAD001]; Novartis) was evaluated in a phase I study with figitumumab (CP-751871; Pfizer), an IGF-1R inhibitor, in which the majority of patients had advanced sarcoma, and the best response of PR was seen in a patient with malignant solitary fibrous tumor. ${ }^{96}$ There are ongoing phase II studies looking at everolimus as a single agent and in combination with imatinib (Gleevec; Novartis) for STS.

\section{Sirolimus}

Sirolimus (rapamycin) is an allosteric mTOR inhibitor that was initially developed as an immunosuppressant and later evaluated for its anticancer properties. Clinical activity for sirolimus alone or in combination with oral cyclophosphamide was reported in four heavily pretreated advanced-sarcoma patients. ${ }^{97}$ This was followed by a phase II study of oral cyclophosphamide and sirolimus in patients with advanced previously treated STS and bone sarcomas. ${ }^{98}$ Ten out of the 47 patients were progression-free for 6 or more months, and the 6-month PFS rate was $21 \%$. However, mTOR levels did not correlate with activity, and sarcomas with higher levels of mTOR activation progressed faster on sirolimus.
Further studies with second-generation mTOR inhibitors described above might help us better understand the biologic correlatives for response and resistance with mTOR pathway inhibitors in STS.

Sirolimus has also been described in the management of malignant perivascular epithelioid tumors (PEComas). These sarcomas are part of a family of diseases that includes angiomyolipomas and lymphangioleiomyomatosis and are seen in patients with tuberous sclerosis, which is associated with mutations in TSC1 and TSC2, which lead to activation of the mTOR pathway. One report in the literature described three patients with malignant PEComas treated with sirolimus, all of whom had evidence of response. ${ }^{99}$ Later the same year, another report described two patients with malignant PEComa who were successfully treated with temsirolimus. ${ }^{100}$

\section{Other novel inhibitors}

Mesenchymal-epithelial transition factor (MET) is a protooncogene encoding the MET receptor tyrosine kinase, that upon stimulation from hepatocyte growth factor/scatter factor induces downstream signaling leading to invasive cellular growth, morphogenic differentiation, and angiogenesis. MET can be detected by immunohistochemistry in $87 \%$ of sarcomas, and higher levels of expression correlate with higher tumor grade. ${ }^{101,102}$ Cabozantinib (XL-184; Exelixis) is a small-molecule inhibitor, primarily targeting MET and VEGFR-2 and leading to inhibition of tumor growth, metastasis, and angiogenesis. Additional targets include RET, AXL, KIT, and TIE-2. Antitumor activity was seen in a phase I study in advanced solid-tumor patients, and SD was noted in one patient with clear-cell sarcoma and another with ASPS. ${ }^{103}$ Further studies will be needed to clarify a potential role in these rare subtypes.

Crizotinib (PF-02341066; Pfizer) is a selective anaplastic lymphoma kinase (ALK) kinase inhibitor with additional activity against c-MET tyrosine kinase. Crizotinib was recently granted accelerated FDA approval for the treatment of patients with metastatic NSCLC harboring ALK translocations, which comprise around 5\% of the NSCLC population. Inflammatory myofibroblastic tumor, a rare aggressive sarcoma in young adults and children, is associated with rearrangements in the ALK locus in around $50 \%$ of patients. One such patient treated with crizotinib experienced a sustained response, which has led to the inclusion of this tumor type in ongoing studies looking at ALK inhibitors in tumors that test positive for ALK translocations. ${ }^{104}$ 
Table 2 Ongoing phase III trials for advanced STS (excluding GIST)

\begin{tabular}{|c|c|c|c|c|}
\hline Sponsor & Intervention & Histologic subtype(s) & Primary end point & Line of therapy \\
\hline ZIOPHARM & $\begin{array}{l}\text { Doxorubicin and palifosfamide-tris } \\
\text { vs doxorubicin and placebo }\end{array}$ & STS excluding GIST & PFS followed by OS & First \\
\hline $\begin{array}{l}\text { Threshold } \\
\text { Pharmaceuticals }\end{array}$ & $\begin{array}{l}\text { TH-302 and doxorubicin } \\
\text { vs doxorubicin }\end{array}$ & STS excluding GIST & OS & First \\
\hline EORTC & Trabectedin vs doxorubicin & $\begin{array}{l}\text { STS excluding subtypes known } \\
\text { to be chemo-insensitive }\end{array}$ & PFS & First \\
\hline $\begin{array}{l}\text { Gynecologic Oncology } \\
\text { Group }\end{array}$ & $\begin{array}{l}\text { Bevacizumab, gemcitabine } \\
\text { and docetaxel vs placebo, } \\
\text { gemcitabine and docetaxel }\end{array}$ & Uterine leiomyosarcoma & PFS & $\begin{array}{l}\text { First (prior hormonal } \\
\text { therapy allowed) }\end{array}$ \\
\hline $\begin{array}{l}\text { Johnson and Johnson } \\
\text { Pharmaceutical Research } \\
\text { and Development }\end{array}$ & $\begin{array}{l}\text { Trabectedin } \\
\text { vs doxorubicin-based regimen }\end{array}$ & Translocation-related sarcoma & PFS & First \\
\hline $\begin{array}{l}\text { Janssen Research } \\
\text { and Development }\end{array}$ & Trabectedin vs dacarbazine & $\begin{array}{l}\text { Liposarcoma (dedifferentiated, } \\
\text { myxoid round cell, pleomorphic) } \\
\text { and leiomyosarcoma }\end{array}$ & OS & Second and beyond \\
\hline Eisai & Eribulin vs dacarbazine & $\begin{array}{l}\text { Leiomyosarcoma and adipocytic } \\
\text { sarcoma }\end{array}$ & OS & Third and beyond \\
\hline $\begin{array}{l}\text { Janssen Research } \\
\text { and Development }\end{array}$ & Trabectedin (open access) & $\begin{array}{l}\text { STS excluding liposarcoma } \\
\text { and leiomyosarcoma }\end{array}$ & Adverse events & $\begin{array}{l}\text { After standard } \\
\text { therapy }\end{array}$ \\
\hline
\end{tabular}

Abbreviations: STS, soft-tissue sarcoma; GIST, gastrointestinal stromal tumor; PFS, progression-free survival; OS, overall survival; EORTC, European Organization for Research and Treatment of Cancer Soft Tissue and Bone Sarcoma group.

The murine double minute 2 (MDM2) oncogene has also been found to be amplified in well-differentiated and dedifferentiated liposarcoma, making it a promising target for therapy. ${ }^{105}$ MDM2 antagonists have demonstrated preclinical activity and are now entering early clinical development, including sarcomaspecific trials in combination with chemotherapy.

There had been a prolonged hiatus in therapeutic advancement for STS other than GIST. It is now heartening to see an increased awareness and interest in STS, with an increasing number of sarcoma trials incorporating novel cytotoxics and targeted therapies. Positive results from two phase III trials were reported last year (SUCCEED and PALETTE), one of which led to the approval of pazopanib for previously treated nonadipocytic STS patients this year. There are a number of promising drugs for advanced STS patients currently in phase III testing (Table 2). This is a relatively exciting time for sarcoma therapy, with new targets and drugs being identified, and national and international collaborations are making large randomized and subtype-specific trials executable.

\section{Disclosure}

The authors report no conflicts of interest in this work.

\section{References}

1. Jemal A, Bray F, Center MM, Ferlay J, Ward E, Forman D. Global cancer statistics. CA Cancer J Clin. 2011;61(2):69-90.

2. Stojadinovic A, Leung DH, Hoos A, Jaques DP, Lewis JJ, Brennan MF. Analysis of the prognostic significance of microscopic margins in 2,084 localized primary adult soft tissue sarcomas. Ann Surg. 2002;235(3): 424-434.
3. O'Sullivan B, Davis AM, Turcotte R, et al. Preoperative versus postoperative radiotherapy in soft-tissue sarcoma of the limbs: a randomised trial. Lancet. 2002;359(9325):2235-2241.

4. [No authors listed]. Adjuvant chemotherapy for localised resectable soft-tissue sarcoma of adults: meta-analysis of individual data. Sarcoma Meta-analysis Collaboration. Lancet. 1997;350(9092):1647-1654.

5. Pervaiz N, Colterjohn N, Farrokhyar F, Tozer R, Figueredo A, Ghert M. A systematic meta-analysis of randomized controlled trials of adjuvant chemotherapy for localized resectable soft-tissue sarcoma. Cancer. 2008;113(3):573-581.

6. Woll PJ, Van Glabbeke M, Hohenberger P, et al. Adjuvant chemotherapy $(\mathrm{CT})$ with doxorubicin and ifosfamide in resected soft tissue sarcoma (STS): interim analysis of a randomised phase III trial. J Clin Oncol. 2007;25(Suppl 18):10008.

7. O'Connor JM, Chacón M, Petracci FE, Chacón RD. Adjuvant chemotherapy in soft tissue sarcoma (STS): a meta-analysis of published data. J Clin Oncol. 2008;26 Suppl:10526.

8. Bramwell V, Rouesse J, Steward W, et al. Adjuvant CYVADIC chemotherapy for adult soft tissue sarcoma - reduced local recurrence but no improvement in survival: a study of the European Organization for Research and Treatment of Cancer Soft Tissue and Bone Sarcoma Group. J Clin Oncol. 1994;12(6):1137-1149.

9. Le Cesne A, Van Glabbeke M, Woll PJ, et al. The end of adjuvant chemotherapy (adCT) era with doxorubicin-based regimen in resected high-grade soft tissue sarcoma (STS): pooled analysis of the two STBSG-EORTC phase III clinical trials. J Clin Oncol. 2008;26 Suppl: 10525.

10. Ferrari A, Gronchi A, Casanova M, et al. Synovial sarcoma: a retrospective analysis of 271 patients of all ages treated at a single institution. Cancer. 2004;101(3):627-634.

11. Eilber FC, Eilber FR, Eckardt J, et al. The impact of chemotherapy on the survival of patients with high-grade primary extremity liposarcoma. Ann Surg. 2004;240(4):686-695; discussion 695-687.

12. Verweij J, Mouridsen HT, Nielssen OS, et al. The present state of the art in chemotherapy for soft tissue sarcomas in adults: the EORTC point of view. Crit Rev Oncol Hematol. 1995;20(3):193-201.

13. Hensley ML, Maki R, Venkatraman E, et al. Gemcitabine and docetaxel in patients with unresectable leiomyosarcoma: results of a phase II trial. J Clin Oncol. 2002;20(12):2824-2831. 
14. Hensley ML, Blessing JA, Degeest K, Abulafia O, Rose PG, Homesley HD. Fixed-dose rate gemcitabine plus docetaxel as second-line therapy for metastatic uterine leiomyosarcoma: a Gynecologic Oncology Group phase II study. Gynecol Oncol. 2008;109(3):323-328.

15. Hensley ML, Blessing JA, Mannel R, Rose PG. Fixed-dose rate gemcitabine plus docetaxel as first-line therapy for metastatic uterine leiomyosarcoma: a Gynecologic Oncology Group phase II trial. Gynecol Oncol. 2008;109(3):329-334.

16. Maki RG, Wathen JK, Patel SR, et al. Randomized phase II study of gemcitabine and docetaxel compared with gemcitabine alone in patients with metastatic soft tissue sarcomas: results of sarcoma alliance for research through collaboration study 002 [corrected]. J Clin Oncol. 2007;25(19):2755-2763.

17. Bay JO, Ray-Coquard I, Fayette J, et al. Docetaxel and gemcitabine combination in 133 advanced soft-tissue sarcomas: a retrospective analysis. Int J Cancer. 2006;119(3):706-711.

18. Sleijfer S, Ouali M, van Glabbeke M, et al. Prognostic and predictive factors for outcome to first-line ifosfamide-containing chemotherapy for adult patients with advanced soft tissue sarcomas: an exploratory, retrospective analysis on large series from the European Organization for Research and Treatment of Cancer-Soft Tissue and Bone Sarcoma Group (EORTC-STBSG). Eur J Cancer. 2010;46(1): $72-83$.

19. Fury MG, Antonescu CR, Van Zee KJ, Brennan MF, Maki RG. A 14-year retrospective review of angiosarcoma: clinical characteristics, prognostic factors, and treatment outcomes with surgery and chemotherapy. Cancer J. 2005;11(3):241-247.

20. Scurr M. Histology-driven chemotherapy in soft tissue sarcomas. Curr Treat Options Oncol. 2011;12(1):32-45.

21. Antman K, Crowley J, Balcerzak SP, et al. An intergroup phase III randomized study of doxorubicin and dacarbazine with or without ifosfamide and mesna in advanced soft tissue and bone sarcomas. J Clin Oncol. 1993;11(7):1276-1285.

22. Bramwell VH, Anderson D, Charette ML. Doxorubicin-based chemotherapy for the palliative treatment of adult patients with locally advanced or metastatic soft-tissue sarcoma: a meta-analysis and clinical practice guideline. Sarcoma. 2000;4(3):103-112.

23. Jelic S, Kovcin V, Milanovic N, et al. Randomised study of highdose epirubicin versus high-dose epirubicin-cisplatin chemotherapy for advanced soft tissue sarcoma. Eur J Cancer. 1997;33(2): 220-225.

24. Le Cesne A, Judson I, Crowther D, et al. Randomized phase III study comparing conventional-dose doxorubicin plus ifosfamide versus high-dose doxorubicin plus ifosfamide plus recombinant human granulocyte-macrophage colony-stimulating factor in advanced soft tissue sarcomas: a trial of the European Organization for Research and Treatment of Cancer/Soft Tissue and Bone Sarcoma Group. J Clin Oncol. 2000;18(14):2676-2684.

25. Hartmann JT, Oechsle K, Huober J, et al. An open label, non-comparative phase II study of gemcitabine as salvage treatment for patients with pretreated adult type soft tissue sarcoma. Invest New Drugs. 2006;24(3):249-253.

26. Pazdur R, Samson MK, Baker LH. Fludarabine phosphate. Phase II evaluation in advanced soft-tissue sarcomas. Am J Clin Oncol. 1987; 10(4):341-343.

27. Reichardt P, Oechsle K, Pink D, et al. An open label, non-comparative phase II study of topotecan as salvage treatment for patients with soft tissue sarcoma. Invest New Drugs. 2003;21(4):481-486.

28. Rose PG, Blessing JA, Soper JT, Barter JF. Prolonged oral etoposide in recurrent or advanced leiomyosarcoma of the uterus: a gynecologic oncology group study. Gynecol Oncol. 1998;70(2):267-271.

29. Woll PJ, Judson I, Lee SM, et al. Temozolomide in adult patients with advanced soft tissue sarcoma: a phase II study of the EORTC Soft Tissue and Bone Sarcoma Group. Eur J Cancer. 1999;35(3):410-412.

30. Van Glabbeke M, Verweij J, Judson I, Nielsen OS. Progression-free rate as the principal end-point for phase II trials in soft-tissue sarcomas. Eur J Cancer. 2002;38(4):543-549.
31. David-Cordonnier MH, Gajate C, Olmea O, et al. DNA and non-DNA targets in the mechanism of action of the antitumor drug trabectedin. Chem Biol. 2005;12(11):1201-1210.

32. Takebayashi Y, Pourquier P, Zimonjic DB, et al. Antiproliferative activity of ecteinascidin 743 is dependent upon transcription-coupled nucleotide-excision repair. Nat Med. 2001;7(8):961-966.

33. Friedman D, Hu Z, Kolb EA, Gorfajn B, Scotto KW. Ecteinascidin743 inhibits activated but not constitutive transcription. Cancer Res. 2002;62(12):3377-3381

34. Takebayashi Y, Goldwasser F, Urasaki Y, Kohlhagen G, Pommier Y. Ecteinascidin 743 induces protein-linked DNA breaks in human colon carcinoma HCT116 cells and is cytotoxic independently of topoisomerase I expression. Clin Cancer Res. 2001;7(1): 185-191.

35. Herrero AB, Martin-Castellanos C, Marco E, Gago F, Moreno S. Cross-talk between nucleotide excision and homologous recombination DNA repair pathways in the mechanism of action of antitumor trabectedin. Cancer Res. 2006;66(16):8155-8162.

36. Delaloge S, Yovine A, Taamma A, et al. Ecteinascidin-743: a marine-derived compound in advanced, pretreated sarcoma patients - preliminary evidence of activity. J Clin Oncol. 2001;19(5): 1248-1255.

37. Yovine A, Riofrio M, Blay JY, et al. Phase II study of ecteinascidin743 in advanced pretreated soft tissue sarcoma patients. J Clin Oncol. 2004;22(5):890-899.

38. Garcia-Carbonero R, Supko JG, Manola J, et al. Phase II and pharmacokinetic study of ecteinascidin 743 in patients with progressive sarcomas of soft tissues refractory to chemotherapy. J Clin Oncol. 2004;22(8):1480-1490.

39. Le Cesne A, Blay JY, Judson I, et al. Phase II study of ET-743 in advanced soft tissue sarcomas: a European Organisation for the Research and Treatment of Cancer (EORTC) soft tissue and bone sarcoma group trial. J Clin Oncol. 2005;23(3):576-584.

40. Huygh G, Clement PM, Dumez H, et al. Ecteinascidin-743: evidence of activity in advanced, pretreated soft tissue and bone sarcoma patients. Sarcoma. 2006;2006:56282.

41. Garcia-Carbonero R, Supko JG, Maki RG, et al. Ecteinascidin-743 (ET-743) for chemotherapy-naive patients with advanced soft tissue sarcomas: multicenter phase II and pharmacokinetic study. J Clin Oncol. 2005;23(24):5484-5492.

42. Gronchi A, Bui BN, Bonvalot S, et al. Phase II clinical trial of neoadjuvant trabectedin in patients with advanced localized myxoid liposarcoma. Ann Oncol. 2012;23(3):771-776.

43. Demetri GD, Chawla SP, von Mehren M, et al. Efficacy and safety of trabectedin in patients with advanced or metastatic liposarcoma or leiomyosarcoma after failure of prior anthracyclines and ifosfamide: results of a randomized phase II study of two different schedules. J Clin Oncol. 2009;27(25):4188-4196.

44. Gomez J, Lázaro LL, Guzman C, Gonzalez A, Misset J, Twelves C. Identification of biochemical parameters that predict the onset of severe toxicities in patients treated with ET-743. Proc Am Soc Clin Oncol. 2000;19:727.

45. Taamma A, Misset JL, Riofrio M, et al. Phase I and pharmacokinetic study of ecteinascidin-743, a new marine compound, administered as a 24-hour continuous infusion in patients with solid tumors. J Clin Oncol. 2001;19(5):1256-1265.

46. Grosso F, Dileo P, Sanfilippo R, et al. Steroid premedication markedly reduces liver and bone marrow toxicity of trabectedin in advanced sarcoma. Eur J Cancer. 2006;42(10):1484-1490.

47. Hingorani P, Zhang W, Piperdi S, et al. Preclinical activity of palifosfamide lysine (ZIO-201) in pediatric sarcomas including oxazaphosphorine-resistant osteosarcoma. Cancer Chemother Pharmacol. 2009;64(4): 733-740.

48. Jones B, Komarnitsky P, Miller GT, Amedio J, Wallner BP. Anticancer activity of stabilized palifosfamide in vivo: schedule effects, oral bioavailability, and enhanced activity with docetaxel and doxorubicin. Anticancer Drugs. 2012;23(2):173-184. 
49. Chugh R, Chawla S, Benjamin R, Heaton J, Stevens J, Schwartz B. Phase I/II study of ZIO-201 in advanced sarcoma. ESMO 32nd Congress; July 5-8, 2007; Lugano, Switzerland.

50. Chawla S, Chua V, Abbadessa G, LoBue L, Lewis J. A study of palifosfamide in combination with doxorubicin: safety and preliminary efficacy. Connective Tissue Oncology Society 14th Annual Meeting; November 13-15, 2008; London, UK.

51. Verschraegen CF, Mita MM, Ryan CW, et al. A phase II, randomized, controlled trial of palifosfamide plus doxorubicin versus doxorubicin in patients with soft tissue sarcoma (PICASSO). J Clin Oncol. 2010; 28(Suppl 15):10004.

52. Duan JX, Jiao H, Kaizerman J, et al. Potent and highly selective hypoxiaactivated achiral phosphoramidate mustards as anticancer drugs. J Med Chem. 2008;51(8):2412-2420.

53. Weiss GJ, Infante JR, Chiorean EG, et al. Phase 1 study of the safety, tolerability, and pharmacokinetics of TH-302, a hypoxia-activated prodrug, in patients with advanced solid malignancies. Clin Cancer Res. 2011;17(9):2997-3004.

54. Ganjoo KN, Cranmer LD, Butrynski JE, et al. A phase I study of the safety and pharmacokinetics of the hypoxia-activated prodrug TH-302 in combination with doxorubicin in patients with advanced soft tissue sarcoma. Oncology. 2011;80(1-2):50-56.

55. Chawla SP, Adkins D, Reed D, et al. TH-302 in combination with doxorubicin in patients with first line advanced soft tissue sarcoma previously untreated with chemotherapy. 2011 Combined Meeting of the Connective Tissue Oncology Society and the Musculoskeletal Tumor Society. October 26-29, 2011; Chicago, US.

56. Schoffski P, Ray-Coquard IL, Cioffi A, et al. Activity of eribulin mesylate in patients with soft-tissue sarcoma: a phase 2 study in four independent histological subtypes. Lancet Oncol. 2011;12(11):1045-1052.

57. Heymach JV. Angiogenesis and antiangiogenic approaches to sarcomas. Curr Opin Oncol. 2001;13(4):261-269.

58. Yoon SS, Segal NH, Olshen AB, Brennan MF, Singer S. Circulating angiogenic factor levels correlate with extent of disease and risk of recurrence in patients with soft tissue sarcoma. Ann Oncol. 2004;15(8): 1261-1266.

59. Sleijfer S, Ray-Coquard I, Papai Z, et al. Pazopanib, a multikinase angiogenesis inhibitor, in patients with relapsed or refractory advanced soft tissue sarcoma: a phase II study from the European organisation for research and treatment of cancer-soft tissue and bone sarcoma group (EORTC study 62043). J Clin Oncol. 2009;27(19):3126-3132.

60. van der Graaf WT, Blay JY, Chawla SP, et al. Pazopanib for metastatic soft-tissue sarcoma (PALETTE): a randomised, double-blind, placebocontrolled phase 3 trial. Lancet. 2012;379(9829):1879-1886.

61. Weiner TM, Liu ET, Craven RJ, Cance WG. Expression of growth factor receptors, the focal adhesion kinase, and other tyrosine kinases in human soft tissue tumors. Ann Surg Oncol. 1994;1(1):18-27.

62. Franklin WA, Christison WH, Colley M, Montag AG, Stephens JK, Hart CE. In situ distribution of the beta-subunit of platelet-derived growth factor receptor in nonneoplastic tissue and in soft tissue tumors. Cancer Res. 1990;50(19):6344-6348.

63. Strumberg D, Richly H, Hilger RA, et al. Phase I clinical and pharmacokinetic study of the novel Raf kinase and vascular endothelial growth factor receptor inhibitor BAY 43-9006 in patients with advanced refractory solid tumors. J Clin Oncol. 2005;23(5):965-972.

64. Maki RG, D'Adamo DR, Keohan ML, et al. Phase II study of sorafenib in patients with metastatic or recurrent sarcomas. J Clin Oncol. 2009; 27(19):3133-3140.

65. von Mehren M, Rankin C, Goldblum JR, et al. Phase 2 Southwest Oncology Group-directed intergroup trial (S0505) of sorafenib in advanced soft tissue sarcomas. Cancer. 2012;118(3):770-776.

66. Ray-Coquard I, Italiano A, Bompas E, et al. Sorafenib for patients with advanced angiosarcoma: a phase II trial from the French Sarcoma Group (GSF/GETO). Oncologist. 2012;17(2):260-266.

67. Gounder MM, Lefkowitz RA, Keohan ML, et al. Activity of sorafenib against desmoid tumor/deep fibromatosis. Clin Cancer Res. 2011; 17(12):4082-4090.
68. Chugh R, Wathen JK, Patel SR, et al. Efficacy of imatinib in aggressive fibromatosis: Results of a phase II multicenter Sarcoma Alliance for Research through Collaboration (SARC) trial. Clin Cancer Res. 2010;16(19):4884-4891.

69. George S, Blay JY, Casali PG, et al. Clinical evaluation of continuous daily dosing of sunitinib malate in patients with advanced gastrointestinal stromal tumour after imatinib failure. Eur $J$ Cancer. 2009;45(11):1959-1968.

70. George S, Merriam P, Maki RG, et al. Multicenter phase II trial of sunitinib in the treatment of nongastrointestinal stromal tumor sarcomas. J Clin Oncol. 2009;27(19):3154-3160.

71. Stacchiotti S, Negri T, Libertini M, et al. Sunitinib malate in solitary fibrous tumor (SFT). Ann Oncol. Epub June 17, 2012.

72. Hensley ML, Sill MW, Scribner DR Jr, et al. Sunitinib malate in the treatment of recurrent or persistent uterine leiomyosarcoma: a Gynecologic Oncology Group phase II study. Gynecol Oncol. 2009;115(3): 460-465.

73. Schwartz GK, Ratain MJ, Undevia SD, et al. Brivanib (BMS-582664) in advanced soft-tissue sarcoma (STS): biomarker and subset results of a phase II randomized discontinuation tria. J Clin Oncol. 2011; 29 Suppl: 10000.

74. Gardner K, Leahy M, Barquin E, et al. Activity of cediranib, a highly potent and selective VEGF signaling inhibitor, in alveolar soft part sarcoma. J Clin Oncol. 2009;27 Suppl 15:10523.

75. Kummar S, Monks A, Ivy SP, et al. An evaluation of cediranib as a new agent for alveolar soft part sarcoma (ASPS). J Clin Oncol. 2011; 29 Suppl:10001

76. Agulnik M, Von Mehren M, Jovanovic B, Brockstein B, Benjamin RS, Evens AM. An open-label multicenter phase II study of bevacizumab for the treatment of angiosarcoma. J Clin Oncol. 2009;27 Suppl 15:10522.

77. Fuller CK, Charlson JA, Dankle SK, Russell TJ. Dramatic improvement of inoperable angiosarcoma with combination paclitaxel and bevacizumab chemotherapy. J Am Acad Dermatol. 2010;63(4):e83-e84.

78. Rosen A, Thimon S, Ternant D, Machet MC, Paintaud G, Machet L. Partial response to bevacizumab of an extensive cutaneous angiosarcoma of the face. Br J Dermatol. 2010;163(1):225-227.

79. D'Adamo DR, Anderson SE, Albritton K, et al. Phase II study of doxorubicin and bevacizumab for patients with metastatic soft-tissue sarcomas. J Clin Oncol. 2005;23(28):7135-7142.

80. Verschraegen CF, Arias-Pulido H, Lee SJ, et al. Phase IB study of the combination of docetaxel, gemcitabine, and bevacizumab in patients with advanced or recurrent soft tissue sarcoma: the Axtell regimen. Ann Oncol. 2012;23(3):785-790.

81. Park MS, Patel SR, Ludwig JA, et al. Activity of temozolomide and bevacizumab in the treatment of locally advanced, recurrent, and metastatic hemangiopericytoma and malignant solitary fibrous tumor. Cancer. 2011;117(21):4939-4947.

82. Choi H, Charnsangavej C, Faria SC, et al. Correlation of computed tomography and positron emission tomography in patients with metastatic gastrointestinal stromal tumor treated at a single institution with imatinib mesylate: proposal of new computed tomography response criteria. J Clin Oncol. 2007;25(13):1753-1759.

83. Rikhof B, de Jong S, Suurmeijer AJ, Meijer C, van der Graaf WT. The insulin-like growth factor system and sarcomas. J Pathol. 2009;217(4): 469-482.

84. Prieur A, Tirode F, Cohen P, Delattre O. EWS/FLI-1 silencing and gene profiling of Ewing cells reveal downstream oncogenic pathways and a crucial role for repression of insulin-like growth factor binding protein 3. Mol Cell Biol. 2004;24(16):7275-7283.

85. Malempati S, Weigel B, Ingle AM, et al. Phase I/II trial and pharmacokinetic study of cixutumumab in pediatric patients with refractory solid tumors and Ewing sarcoma: a report from the Children's Oncology Group. J Clin Oncol. 2012;30(3):256-262.

86. Tolcher AW, Sarantopoulos J, Patnaik A, et al. Phase I, pharmacokinetic, and pharmacodynamic study of AMG 479, a fully human monoclonal antibody to insulin-like growth factor receptor 1 . J Clin Oncol. 2009;27(34):5800-5807. 
87. Schoffski P, Adkins D, Blay J, et al. Phase II trial of anti-IGF-IR antibody cixutumumab in patients with advanced or metastatic soft-tissue sarcoma and Ewing family of tumors. J Clin Oncol. 2011;29 Suppl 15: 10004.

88. Kurmasheva RT, Dudkin L, Billups C, Debelenko LV, Morton CL, Houghton PJ. The insulin-like growth factor-1 receptor-targeting antibody, CP-751,871, suppresses tumor-derived VEGF and synergizes with rapamycin in models of childhood sarcoma. Cancer Res 2009;69(19):7662-7671.

89. Naing A, LoRusso P, Fu S, et al. Insulin growth factor-receptor (IGF-1R) antibody cixutumumab combined with the mTOR inhibitor temsirolimus in patients with refractory Ewing's sarcoma family tumors. Clin Cancer Res. 2012;18(9):2625-2631.

90. Schwartz GK TW, Qin L, et al. A phase II multicenter study of the IGF-1 receptor antibody cixutumumab (A12) and the mTOR inhibitor temsirolimus (TEM) in patients (pts) with refractory IGF-1R positive $(+)$ and negative $(-)$ bone and soft tissue sarcomas (STS). J Clin Oncol. 2012;30 Suppl:10003.

91. Chugh R, Griffith KA, Brockstein B, Undevia SD, Stadler WM, Schuetze S. Phase I study of doxorubicin (D) plus anti-insulin-like growth factor 1 receptor (IGF-1R) antibody cixutumumab (IMC-A12) in advanced soft tissue sarcoma (STS). J Clin Oncol. 2012;30 Suppl: 10028 .

92. Schmelzle T, Hall MN. TOR, a central controller of cell growth. Cell. 2000;103(2):253-262.

93. Brown EJ, Schreiber SL. A signaling pathway to translational control. Cell. 1996;86(4):517-520.

94. Chawla SP, Staddon AP, Baker LH, et al. Phase II study of the mammalian target of rapamycin inhibitor ridaforolimus in patients with advanced bone and soft tissue sarcomas. J Clin Oncol. 2012;30(1):78-84.

95. Okuno S, Bailey H, Mahoney MR, et al. A phase 2 study of temsirolimus (CCI-779) in patients with soft tissue sarcomas: a study of the Mayo phase 2 consortium (P2C). Cancer. 2011;117(15):3468-3475.

96. Quek R, Wang Q, Morgan JA, et al. Combination mTOR and IGF-1R inhibition: phase I trial of everolimus and figitumumab in patients with advanced sarcomas and other solid tumors. Clin Cancer Res. 2011; 17(4):871-879.
97. Schuetze SM, Baker LH, Maki RG. Sirolimus reduced tumor-related morbidity and resulted in biochemical and radiographic response in patients with progressive sarcoma. J Clin Oncol. 2006;24 Suppl 18: Abstr 9503.

98. Schuetze S, Zhao L, Chugh R, et al. Results of a phase II trial of sirolimus (S) and cyclophosphamide (C) in advanced sarcoma. J Clin Oncol. 2011;29 Suppl:10003.

99. Wagner AJ, Malinowska-Kolodziej I, Morgan JA, et al. Clinical activity of mTOR inhibition with sirolimus in malignant perivascular epithelioid cell tumors: targeting the pathogenic activation of mTORC1 in tumors. J Clin Oncol. 2010;28(5):835-840.

100. Italiano A, Delcambre C, Hostein I, et al. Treatment with the mTOR inhibitor temsirolimus in patients with malignant PEComa. Ann Oncol. 2010;21(5):1135-1137.

101. Kuhnen C, Muehlberger T, Honsel M, Tolnay E, Steinau HU, Muller KM. Impact of c-Met expression on angiogenesis in soft tissue sarcomas: correlation to microvessel-density. J Cancer Res Clin Oncol. 2003;129(7):415-422.

102. Oda Y, Sakamoto A, Saito T, Kinukawa N, Iwamoto Y, Tsuneyoshi M. Expression of hepatocyte growth factor (HGF)/scatter factor and its receptor c-MET correlates with poor prognosis in synovial sarcoma. Hum Pathol. 2000;31(2):185-192.

103. Kurzrock R, Sherman SI, Ball DW, et al. Activity of XL184 (Cabozantinib), an oral tyrosine kinase inhibitor, in patients with medullary thyroid cancer. J Clin Oncol. 2011;29(19):2660-2666.

104. Butrynski JE, D’Adamo DR, Hornick JL, et al. Crizotinib in ALKrearranged inflammatory myofibroblastic tumor. N Engl J Med. 2010; 363(18):1727-1733.

105. Singer S, Socci ND, Ambrosini G, et al. Gene expression profiling of liposarcoma identifies distinct biological types/subtypes and potential therapeutic targets in well-differentiated and dedifferentiated liposarcoma. Cancer Res. 2007;67(14):6626-6636.
Cancer Management and Research

\section{Publish your work in this journal}

Cancer Management and Research is an international, peer-reviewed open access journal focusing on cancer research and the optimal use of preventative and integrated treatment interventions to achieve improved outcomes, enhanced survival and quality of life for the cancer patient The journal welcomes original research, clinical \& epidemiological

\section{Dovepress}

studies, reviews \& evaluations, guidelines, expert opinion \& commentary, case reports \& extended reports. The manuscript management system is completely online and includes a very quick and fair peerreview system, which is all easy to use. Visit http://www.dovepress.com/ testimonials.php to read real quotes from published authors. 